\title{
Structural and Optical Properties of Aluminum Nitride Thin Films Deposited by Pulsed DC Magnetron Sputtering
}

\author{
R. K. Choudhary, ${ }^{1}$ P. Mishra, ${ }^{1}$ A. Biswas, ${ }^{2}$ and A. C. Bidaye ${ }^{1}$ \\ ${ }^{1}$ Materials Processing Division, Bhabha Atomic Research Centre, Trombay, Mumbai 400085, India \\ ${ }^{2}$ Applied Spectroscopy Division, Bhabha Atomic Research Centre, Trombay, Mumbai 400085, India \\ Correspondence should be addressed to R. K. Choudhary; rupeshkr@barc.gov.in
}

Received 17 July 2013; Accepted 28 August 2013

Academic Editors: E. J. Nassar and Y. Sun

Copyright ( 2013 R. K. Choudhary et al. This is an open access article distributed under the Creative Commons Attribution License, which permits unrestricted use, distribution, and reproduction in any medium, provided the original work is properly cited.

\begin{abstract}
Aluminum nitride thin films were deposited on $\mathrm{Si}(100)$ substrate by pulsed DC (asymmetric bipolar) reactive magnetron sputtering under variable nitrogen flow in a gas mixture of argon and nitrogen. The deposited film was characterized by grazing incidence $\mathrm{X}$-ray diffraction (GIXRD), atomic force microscope (AFM), spectroscopic ellipsometry, and secondary ion mass spectroscopy (SIMS). GIXRD results have shown (100) reflection of wurtzite AlN, whereas AFM micrographs have revealed very fine grained microstructure with average roughness in the range $6-8 \mathrm{~nm}$. Spectroscopic ellipsometry measurements have indicated the band gap and refractive index of the film in the range 5.0-5.48 eV and 1.58-1.84, respectively. SIMS measurement has indicated the presence of oxygen in the film.
\end{abstract}

\section{Introduction}

Aluminum nitride, a III-V family compound, has excellent combination of physical, chemical, and mechanical properties. High-quality films of aluminum nitride have been used in various devices and sensors including the optical and optoelectronic devices. As far as the optical and optoelectronic applications are concerned, wide band gap $(\sim 6.2 \mathrm{eV})$ along with high-refractive index $(\sim 2.0)$ and low-absorption coefficient $\left(<10^{-3}\right)$ makes AlN a very attractive material for these applications [1]. In addition to this, thermal and chemical stability of AlN films make it suitable for applications in difficult environment. Today, AlN films/coatings have been grown by several methods which include pulsed laser deposition [2], reactive molecular beam epitaxy [3], vacuum arc/cathodic arc deposition [4], DC/RF reactive sputtering [5-7], ion beam sputtering [8], metal-organic chemical vapor deposition (MOCVD) [9], and miscellaneous [10] other techniques. Due to simplicity, reproducibility, ease of scaling up, and lower cost, magnetron sputtering is one of the common methods for growing AlN films for various applications. As already known, it is difficult to obtain good quality insulating films by DC magnetron sputtering, and $\mathrm{RF}$ magnetron sputtering has the disadvantage of lower deposition rate and higher cost of the RF power, whereas pulsed DC magnetron sputtering method has the advantage of higher deposition rate and it is suitable for producing good quality cost-effective dielectric films $[11,12]$.

Properties of AlN films depend upon the crystal structure, crystal orientation, microstructure, and chemical composition, which in turn depend upon the deposition conditions such as sputtering power, pulse frequency, duty cycle, growth temperature, nitrogen/argon flow ratio, and sputtering gas pressure. Effect of nitrogen/argon flow ratio on the optical properties of AlN films have been widely reported for DC and RF magnetron sputtering $[5,6,13]$, but the same has not been studied in detail for pulsed DC magnetron sputtering. Therefore, in this study, we have deposited aluminum nitride thin films by pulsed DC reactive magnetron sputtering for a wide range of nitrogen/argon flow ratio and their effect on optical properties has been studied using the spectroscopic ellipsometry technique. Also, in the same work, study on structure and morphology of the film has been conducted using GIXRD and AFM. 


\section{Experimental Methods}

A reactive pulsed DC balanced magnetron sputtering system coupled with asymmetric bipolar DC generator (reverse bias voltage: $+36 \mathrm{~V}$ ) was employed to deposit the AlN film with 99.99\% pure aluminum used as a target material. Properly cleaned single crystal silicon wafer having (100) orientation was used as the substrate. Final cleaning of the substrate was done in situ by $\mathrm{Ar}^{+}$ion bombardment for $30 \mathrm{~min}$ at a biasing voltage of $-800 \mathrm{~V}$ and a pressure of $10^{-1}$ mbar. Deposition was carried out at a working pressure of $1.5 \times 10^{-3}$ mbar in argon and nitrogen atmosphere. Numerical values of key deposition parameters are listed in Table 1.

Crystal structure of the deposited film was revealed by GIXRD measurement at monochromatized $\mathrm{CuK}_{\alpha}(\lambda=$ $0.154 \mathrm{~nm}$ ) wavelength for an incidence angle of $1^{\circ}$. The experimental GIXRD patterns were matched with JCPDS file and the peak of aluminum nitride was identified. Surface morphology and roughness of the film were analyzed by AFM in tapping mode. Optical properties were measured using a phase modulated spectroscopic ellipsometer in the wavelength range 300-1200 $\mathrm{nm}$. Chemical composition of the film was qualitatively analyzed by SIMS.

\section{Results and Discussion}

The rate of deposition of AlN (calculated as thickness measured in ellipsometry divided by the deposition time) for various flow ratio of nitrogen/argon is shown in Figure 1. It is clear that deposition rate decreases continuously with increase in flow ratio of nitrogen/argon mainly because of the increased proportion of $\mathrm{N}^{+}$or $\mathrm{N}_{2}{ }^{+}$ions which transfer lower momentum to the target compared to the massive $\mathrm{Ar}^{+}$ ion; consequently, energy and fluence of the sputtered atoms decrease and this leads to a gradual fall in the growth rate of the film [14].

The AlN films deposited for different flow ratio of nitrogen/argon had different colours due to variation in stoichiometry [15]. Films deposited at a higher flow ratio were violet, whereas for intermediate flow ratios, colour was blue and for still lower flows ratio, it was yellow. Exact variation in colour is given in Table 2 .

3.1. GIXRD and AFM Results. The GIXRD pattern is shown in Figure 2. It has been found that, for all flow ratio of nitrogen/argon, only the low intensity (100) reflection of wurtzite hexagonal phase of AlN was found with an appreciable amount of shift. This may be due to poor crystallinity of films with large amount of stress present, probably due to the low deposition temperature and sputtering power. In the present study, we could not obtain (001) reflection at any nitrogen/argon flow ratio. The reason may be that the (001) plane is the lowest energy plane with the highest atom density which requires high adatom mobility for its growth and the same can be achieved at a higher growth temperature and target power.

Figures 3(a)-3(c) shows the AFM micrographs. The micrographs show that at $80 \%$ flow ratio of nitrogen/argon,
TABLE 1: Deposition parameters for growth of AlN thin film.

\begin{tabular}{lc}
\hline Parameter & Numerical value \\
\hline Base pressure & $1.1 \times 10^{-5} \mathrm{mbar}$ \\
Power density of cathode & $3.3 \mathrm{~W} / \mathrm{cm}^{2}$ \\
Pulse frequency & $125 \mathrm{kHz}$ \\
Duty cycle & $75 \%$ \\
Target-to-substrate distance & $7.5 \mathrm{~cm}$ \\
Total gas $\left(\mathrm{Ar}+\mathrm{N}_{2}\right)$ flow rate & $10 \mathrm{sccm}$ \\
Substrate temperature & No external heating $\left(\sim 100^{\circ} \mathrm{C}\right)$ \\
\hline
\end{tabular}

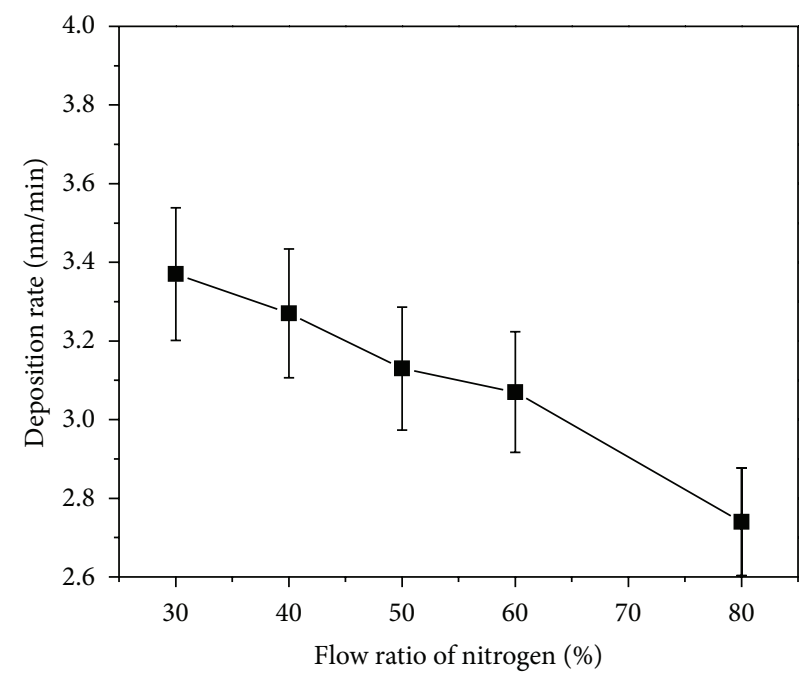

FIGURE 1: Deposition rate of AlN for different nitrogen/argon flow ratio.

TABLE 2: Variation in colour of AlN films with nitrogen/argon flow ratio.

\begin{tabular}{lcc}
\hline $\mathrm{N}_{2} /$ Ar flow ratio (\%) & Deposition time (min) & Colour of the film \\
\hline 30 & 60 & Yellow \\
40 & 60 & Pink \\
50 & 90 & Blue \\
60 & 90 & Blue \\
80 & 90 & Violet \\
\hline
\end{tabular}

surface morphology was uniform with random presence of elongated grains at few locations, whereas at 50 and 30\% flow ratio, grains were of spherical and conical shapes, respectively. The measured average roughness $\left(R_{a}\right)$ values showed no marked effect of varying the nitrogen/argon flow ratio; for all the films, $R_{a}$ values were in the range $6-8 \mathrm{~nm}$. Some authors have reported decreased roughness of AlN film with increasing flow ratio of nitrogen/argon, attributing it to the lower growth rate of the film [14].

3.2. Spectroscopic Ellipsometry Results. In ellipsometry, the optical property is measured by measuring the complex 


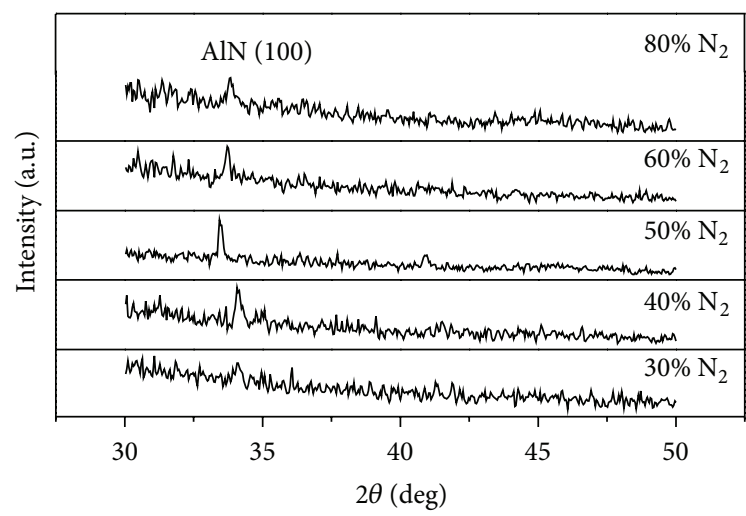

FIGURE 2: GIXRD pattern of AlN film deposited for various flow ratio of nitrogen/argon.

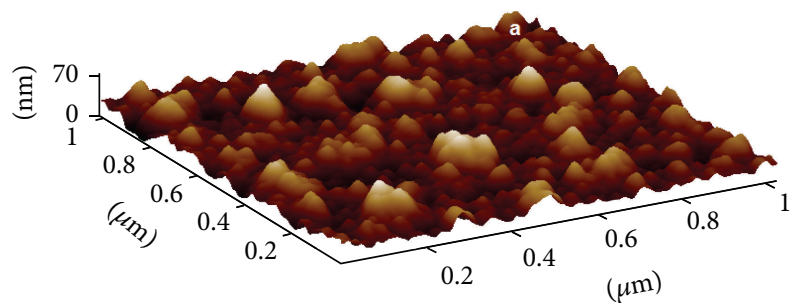

(a)

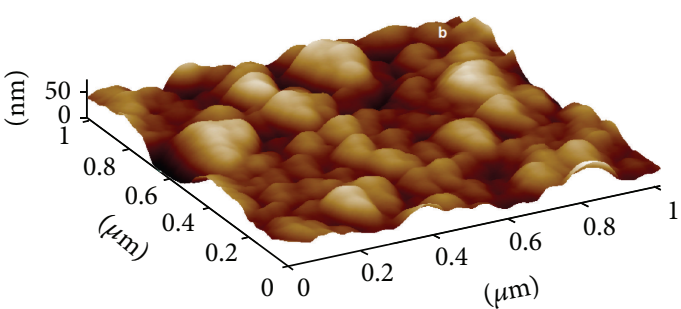

(b)

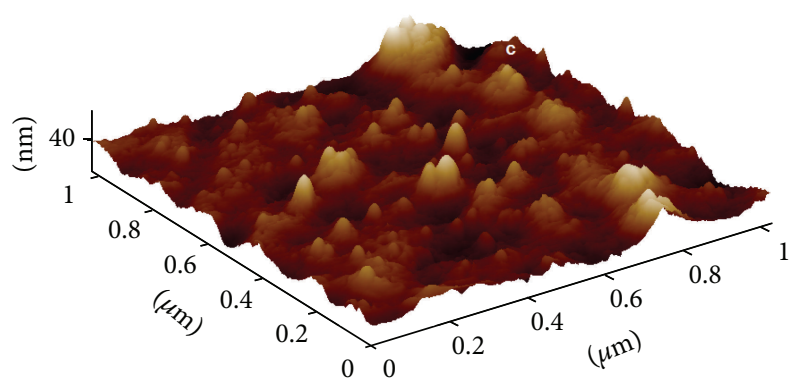

(c)

FIGURE 3: AFM micrographs of AlN film deposited for (a) 30, (b) 50, and (c) $80 \%$ flow ratio of nitrogen/argon.

reflectance ratio of incident light on a sample [16, 17]. The reflectance ratio is defined as

$$
\rho=\frac{r_{p}}{r_{s}}=\tan (\psi) e^{i \Delta} .
$$

Here, $\tan (\psi)$ is known as the amplitude ratio and $\Delta$ is called the phase shift and $r_{p}$ and $r_{s}$ represent the complex Fresnel

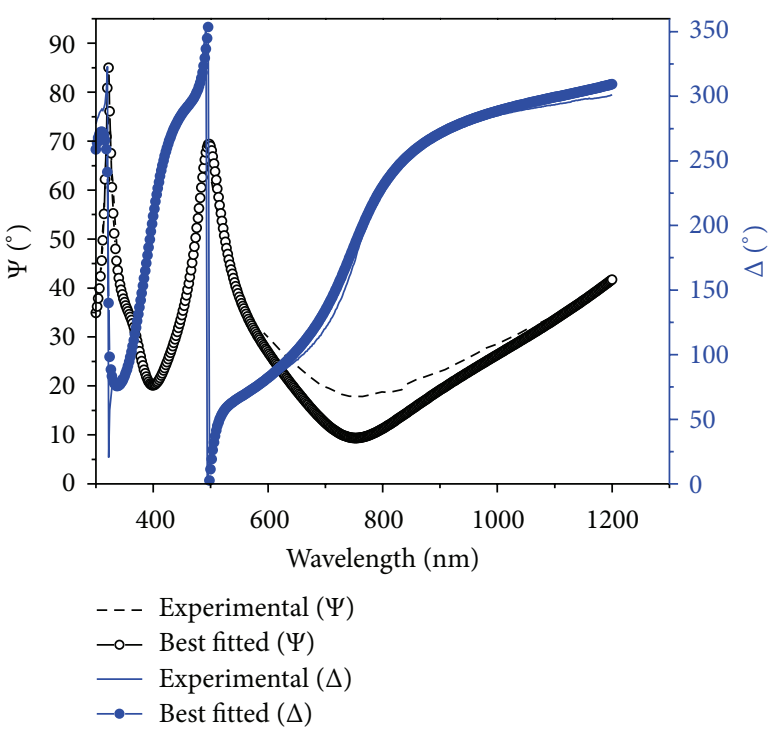

FIGURE 4: Experimental $\Psi$ and $\Delta$ versus wavelength along with bestfit theoretical curve for AlN thin film deposited on $\mathrm{Si}(100)$ at $80 \%$ flow ratio of nitrogen/argon. Fitting was done with Tauc-Lorentz model.

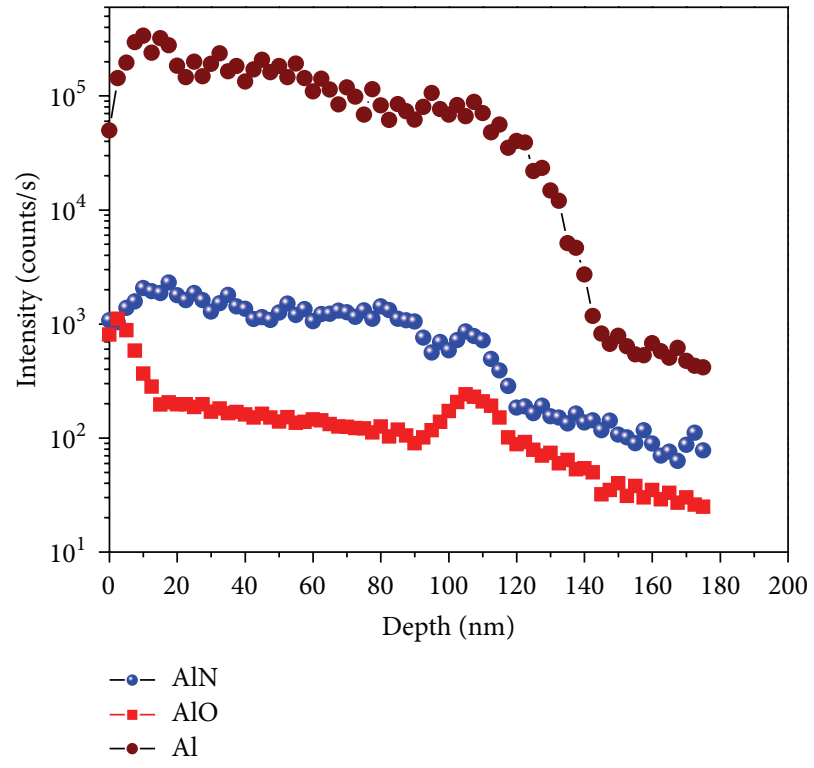

FIGURE 5: SIMS composition depth profile of AlN thin film deposited on Si (100).

coefficients for light parallel and perpendicular to the plane of incidence, respectively.

Figure 4 shows the experimental and the best fitted spectra of the ellipsometric parameters $\Psi$ and $\Delta$. During fitting, a two-layer sample structure was assumed on the silicon substrate. The top layer was assumed to be $50 \%$ void and $50 \% \mathrm{AlN}$, whereas, the lower layer was assumed as bulk $(100 \% \mathrm{AlN})$. This is a well established technique in ellipsometry. The optical property of AlN film was generated 


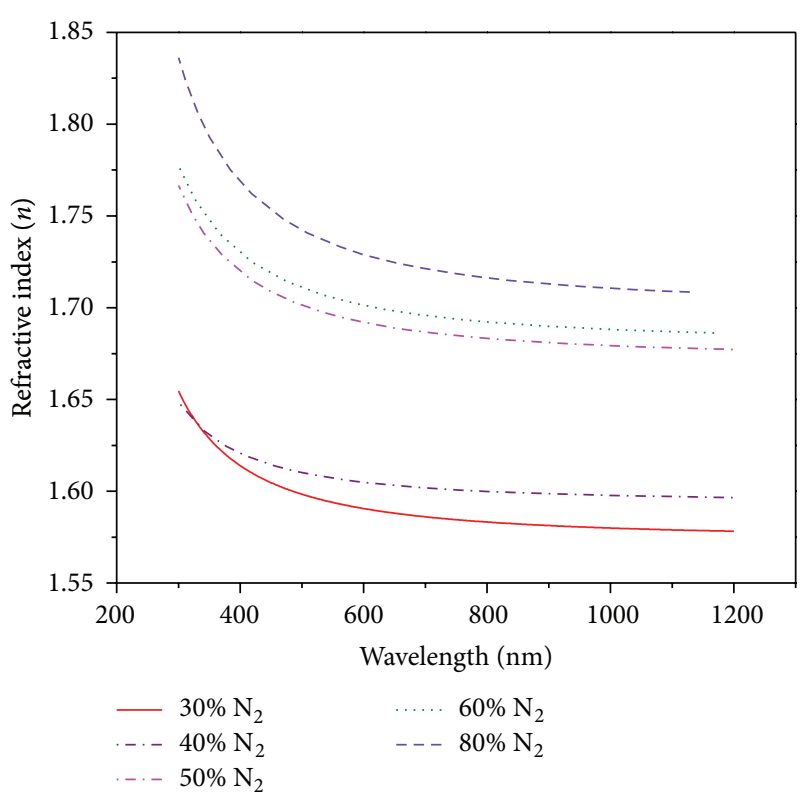

FIGURE 6: Nitrogen/argon flow ratio-dependent refractive indices of AlN thin film.

using the Tauc-Lorentz model. This model was used due to the poor crystalline nature of the deposited film.

The dielectric response of a material which is ultimately related to the ellipsometric parameters $\Psi$ and $\Delta$ is described by a complex function as follows:

$$
\varepsilon=\varepsilon_{1}-i \varepsilon_{2} .
$$

The expression for real part is described by Kramers-Kronig equation [18], which is written as

$$
\varepsilon_{1}=\varepsilon_{\infty}+\frac{2}{\pi} P \int_{E_{g}}^{\infty} \frac{\xi \varepsilon_{2}(\epsilon)}{\xi^{2}-E^{2}} d \xi .
$$

Here, $\varepsilon_{\infty}$ represents the contribution of the optical transition at a higher energy.

The Tauc-Lorentz model gives an expression for the imaginary part $\left(\varepsilon_{2}\right)[18]$ as follows

$$
\varepsilon_{2}= \begin{cases}\frac{A E_{0} \Gamma\left(E-E_{g}\right)^{2}}{\left(E^{2}-E_{0}^{2}\right)^{2}+\Gamma^{2} E^{2}} \frac{1}{E} & \left(E>E_{g}\right) \\ 0 & \left(E \leq E_{g}\right),\end{cases}
$$

where $E_{g}$ is the band gap, $E_{0}$ is the peak transition energy, $\Gamma$ is the broadening parameter, and $A$ is the optical transition matrix element.

Table 3 shows the measured ellipsometric data of aluminum nitride film. From this table, it can be observed that there is a decrease in band gap from 5.48 to $5.00 \mathrm{eV}$ and a substantial decrease in $\varepsilon_{\infty}$ (optical contribution to the dielectric function at a higher photon energy) when the nitrogen/argon flow ratio was increased from 30 to $80 \%$. Similar results on band gap variation of AlN thin films have been reported by García-Méndez et al. [19]. However, our results are contrary
TABLE 3: Measured ellipsometric data of wurtzite AlN.

\begin{tabular}{lccc}
\hline $\mathrm{N}_{2}$ /Ar flow ratio (\%) & Thickness $(\mathrm{nm})$ & Band gap $E_{g}(\mathrm{eV})$ & $\varepsilon_{\mathrm{\infty}}$ \\
\hline 30 & 202 & 5.48 & 1.47 \\
40 & 196 & 5.48 & 1.79 \\
50 & 282 & 5.40 & 1.47 \\
60 & 276 & 5.47 & 1.39 \\
80 & 247 & 5.00 & 0.94 \\
\hline
\end{tabular}

to those of Cho [13] and Wang et al. [15], who have used $\mathrm{RF}$ magnetron sputtering technique. Cho has attributed the increase in band gap to consistently improved crystallinity and stoichiometry of the films. However, Dumitru et al. [20] and Drüsedau and Koppenhagen [21] have observed different optical properties of AlN films deposited by DC and RF magnetron sputtering under identical operating conditions. A probable explanation for the decrease in band gap as observed in our work could be as follows. In our experiments, although high-purity argon and nitrogen gases $(<2 \mathrm{vpm}$ oxygen) were used, nitrogen was further purified to a vpb level of oxygen impurity before introducing it into the deposition chamber. This resulted in lower oxygen content in the chamber/deposit at higher nitrogen/argon flow ratios. This, in turn, reduced the proportion of the more ionic Al-O bonds over the Al-N bonds in the deposit which ultimately resulted in decreased band gap. Our explanation for decrease in band gap of AlN is based on the similar explanation given for $\mathrm{TiO}_{x} \mathrm{~N}_{y}$ films by Mohamed et al. [22]. To detect $\mathrm{AlO}$ in the film, one sample was analyzed in SIMS. The SIMS measurement (Figure 5) confirmed presence of AlO together with AlN in the deposited film.

Figure 6 shows the plot of refractive index versus wavelength of light for AlN films; it is clear that refractive index of sputtered AlN films depends on flow ratio of nitrogen/argon greatly. For a flow ratio greater than $50 \%$, refractive index of the films has been in the range 1.67-1.84, which is lower than the reported values mostly because of the porous nature of the film. For lower flow ratios, refractive index of AlN has been observed to decrease because of the formation of nonstoichiometric films [23].

\section{Conclusions}

AlN thin films were deposited on silicon substrates by pulsed DC reactive magnetron sputtering. The deposited film has shown wurtzite crystal structure with (100) reflection, and flow ratio of nitrogen/argon has been found to have a marked effect on its optical properties. The deposited films exhibited a decreased band gap from 5.48 to $5.0 \mathrm{eV}$ with increasing flow ratio of nitrogen/argon. Similarly, refractive index of the films was in the range $1.58-1.84$.

\section{References}

[1] V. Dimitrova, D. Manova, and E. Valcheva, "Optical and dielectric properties of dc magnetron sputtered AlN thin films correlated with deposition conditions," Materials Science and Engineering B, vol. 68, no. 1, pp. 1-4, 1999. 
[2] R. D. Vispute, H. Wu, and J. Narayan, "High quality epitaxial aluminum nitride layers on sapphire by pulsed laser deposition," Applied Physics Letters, vol. 67, pp. 1549-1551, 1995.

[3] T. Schupp, K. Lischka, and D. J. As, "MBE growth of atomically smooth non-polar cubic AlN," Journal of Crystal Growth, vol. 312, no. 9, pp. 1500-1504, 2010.

[4] H. Takikawa, K. Kimura, R. Miyano et al., "Effect of substrate bias on AlN thin film preparation in shielded reactive vacuum arc deposition," Thin Solid Films, vol. 386, no. 2, pp. 276-280, 2001.

[5] H. Cheng, Y. Sun, J. X. Zhang, Y. B. Zhang, S. Yuan, and P. Hing, "AlN films deposited under various nitrogen concentrations by RF reactive sputtering," Journal of Crystal Growth, vol. 254, no. 1-2, pp. 46-54, 2003.

[6] S. Venkataraj, D. Severin, R. Drese, F. Koerfer, and M. Wuttig, "Structural, optical and mechanical properties of aluminium nitride films prepared by reactive DC magnetron sputtering," Thin Solid Films, vol. 502, no. 1-2, pp. 235-239, 2006.

[7] A. Mahmood, N. Rakov, and M. Xiao, "Influence of deposition conditions on optical properties of aluminum nitride (AlN) thin films prepared by DC-reactive magnetron sputtering," Materials Letters, vol. 57, no. 13-14, pp. 1925-1933, 2003.

[8] H.-Y. Chen, S. Han, and H. C. Shih, "The characterization of aluminum nitride thin films prepared by dual ion beam sputtering," Surface and Coatings Technology, vol. 200, no. 10, pp. 3326-3329, 2006.

[9] C.-M. Zetterling, M. Östling, K. Wongchotigul et al., "Investigation of aluminum nitride grown by metal-organic chemicalvapor deposition on silicon carbide," Journal of Applied Physics, vol. 82, no. 6, pp. 2990-2995, 1997.

[10] R. Thapa, B. Saha, and K. K. Chattopadhyay, "Synthesis of cubic aluminum nitride by VLS technique using gold chloride as a catalyst and its optical and field emission properties," Journal of Alloys and Compounds, vol. 475, no. 1-2, pp. 373-377, 2009.

[11] P. J. Kelly and R. D. Arnell, "Magnetron sputtering: a review of recent developments and applications," Vacuum, vol. 56, no. 3, pp. 159-172, 2000.

[12] J. Sellers, "Asymmetric bipolar pulsed DC: the enabling technology for reactive PVD," Surface and Coatings Technology, vol. 98, no. 1-3, pp. 1245-1250, 1998.

[13] S. Cho, "Effect of nitrogen flow ratio on the structural and optical properties of aluminum nitride thin films," Journal of Crystal Growth, vol. 326, no. 1, pp. 179-182, 2011.

[14] M. A. Moreira, I. Doi, J. F. Souza, and J. A. Diniz, "Electrical characterization and morphological properties of AlN films prepared by dc reactive magnetron sputtering," Microelectronic Engineering, vol. 88, no. 5, pp. 802-806, 2011.

[15] D.-Y. Wang, Y. Nagahata, M. Masuda, and Y. Hayashi, "Effect of nonstoichiometry upon optical properties of radio frequency sputtered Al-N thin films formed at various sputtering pressures," Journal of Vacuum Science and Technology A, vol. 14, no. 6, pp. 3092-3099, 1996.

[16] H. Arwin, M. Poksinski, and K. Johansen, "Total internal reflection ellipsometry: principles and applications," Applied Optics, vol. 43, no. 15, pp. 3028-3036, 2004.

[17] J. N. Hilfiker, N. Singh, T. Tiwald et al., "Survey of methods to characterize thin absorbing films with spectroscopic ellipsometry," Thin Solid Films, vol. 516, no. 22, pp. 7979-7989, 2008.

[18] B. Von Blanckenhagen, D. Tonova, and J. Ullmann, "Application of the Tauc-Lorentz formulation to the interband absorption of optical coating materials," Applied Optics, vol. 41, no. 16, pp. 3137-3141, 2002.
[19] M. García-Méndez, S. Morales-Rodríguez, R. Machorro, and W. De La Cruz, "Characterization of ALN thin films deposited by DC reactive magnetron sputtering," Revista Mexicana de Fisica, vol. 54, no. 4, pp. 271-278, 2008.

[20] V. Dumitru, C. Morosanu, V. Sandu, and A. Stoica, "Optical and structural differences between $\mathrm{RF}$ and $\mathrm{DC} \mathrm{Al}_{x} \mathrm{~N}_{y}$ magnetron sputtered films," Thin Solid Films, vol. 359, no. 1, pp. 17-20, 2000.

[21] T. P. Drüsedau and K. Koppenhagen, "Substrate heating by sputter-deposition of AlN: the effects of dc and rf discharges in nitrogen atmosphere," Surface and Coatings Technology, vol. 153, no. 2-3, pp. 155-159, 2002.

[22] S. H. Mohamed, O. Kappertz, J. M. Ngaruiya et al., "Influence of nitrogen content on properties of direct current sputtered $\mathrm{TiO}_{x} \mathrm{~N}_{y}$ films," Physica Status Solidi A, vol. 201, no. 1, pp. 90102, 2004.

[23] J. Borges, N. P. Barradas, E. Alves et al., "Influence of stoichiometry and structure on the optical properties of $\mathrm{AIN}_{x} \mathrm{O}_{y}$ films," Journal of Physics D, vol. 46, pp. 1-11, 2013. 

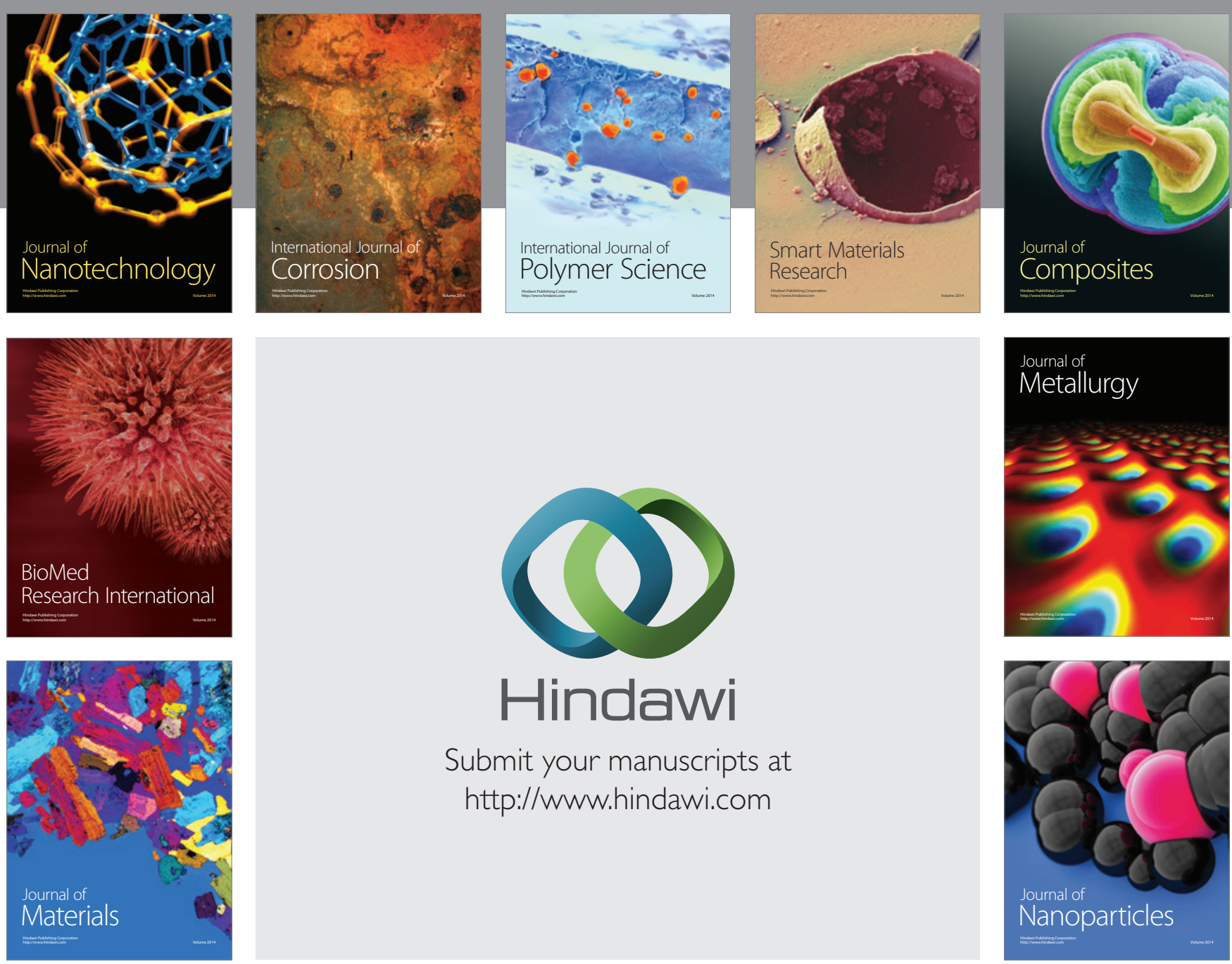

Submit your manuscripts at http://www.hindawi.com
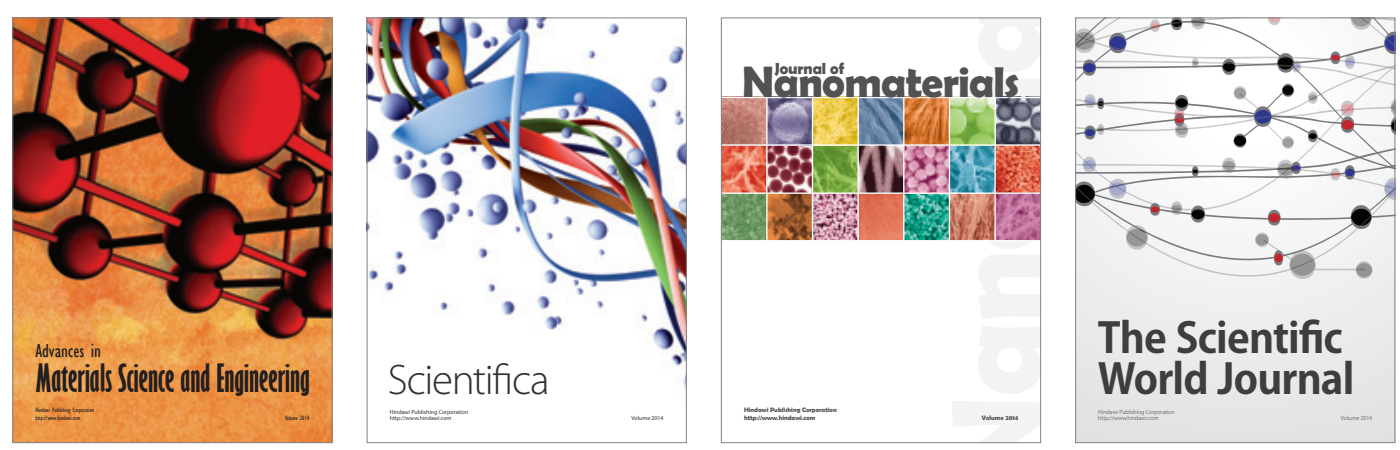

\section{The Scientific World Journal}
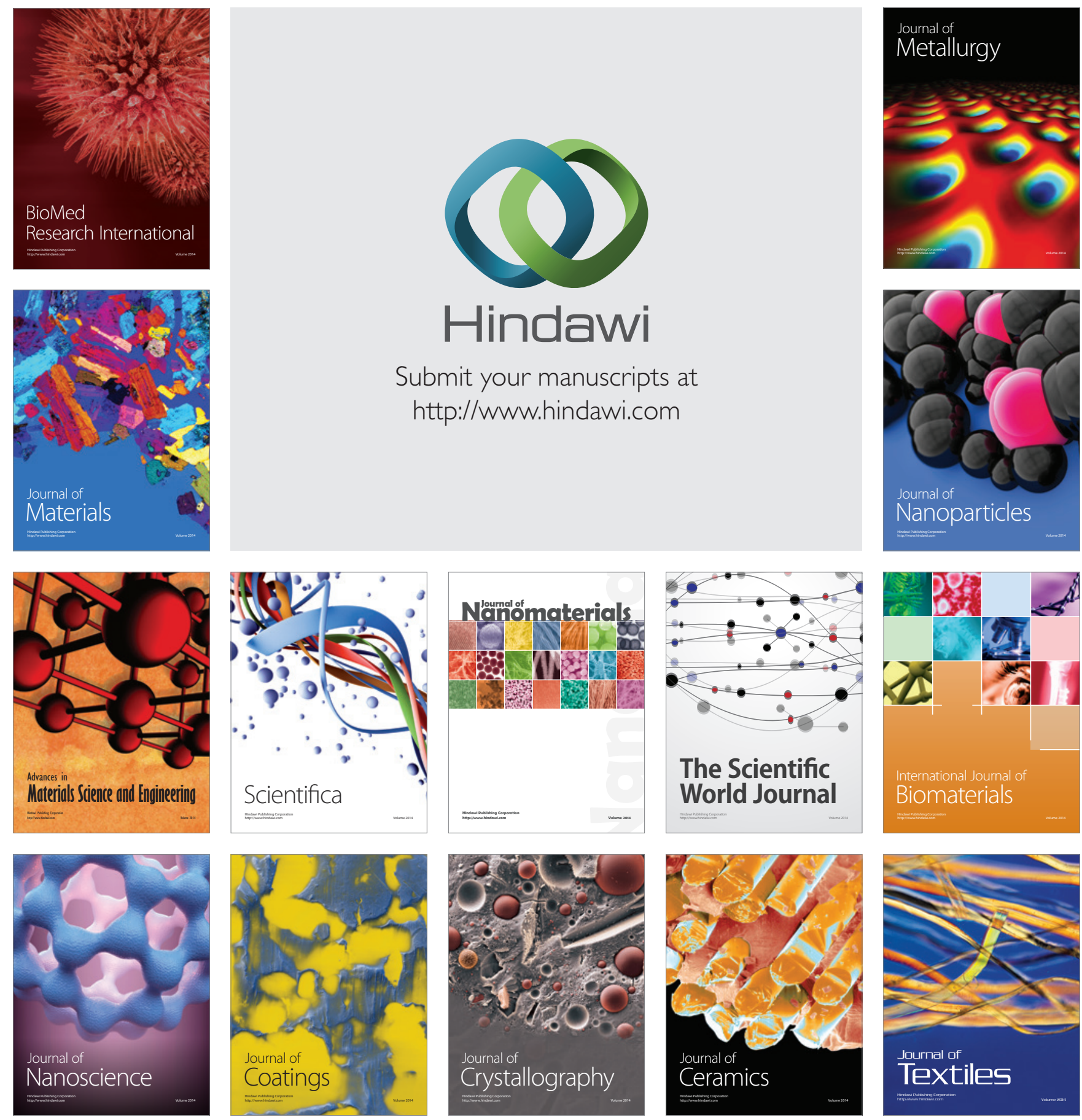